\title{
The determinants of pain revisited: Coordinates in sensory space
}

\author{
Kenneth L Casey MD ${ }^{1}$, Jürgen Lorenz MD Drmed ${ }^{1,2}$
}

\author{
KL Casey, J Lorenz. \\ The determinants of pain revisited: Coordinates in \\ sensory space.
}

Pain Res Manage 2000;5(3):197-204.

Ron Melzack recognized that the gate control hypothesis of 1965 was incomplete. This led to the publication of a book chapter that would someday be referred to by some as 'the classical view' of pain mechanisms. However, this paper presented some conceptual problems for research on pain mechanisms by using the term 'motivational-affective' to define a determinant of pain. To facilitate research and eventually improve practice, the determinants of pain need to be identified and quantified more clearly. In the present article, three critical dimensions of sensory experience that define pain and related sensory experiences are identified: sensory salience, affect and motivational dominance. The authors show that each of these dimensions can be measured and are mediated by specific neurophysiological mechanisms. Pain and other somatic sensations emerge from the conjoint actions of these neurophysiological systems and fall within unambiguously defined coordinates of the three-dimensional sensory surface that they form. Pain mechanisms would be better understood if research focused on the physiology and psychology of these fundamental sensory dimensions and included a wider range of sensory systems.

Key Words: Affect; Gate control hypothesis; Motivational dominance; Sensory salience

\section{Revue des facteurs de la douleur : Coordonnées de l'espace sensoriel}

RÉSUMÉ : Ron Melzack a réalisé que l'hypothèse du contrôle par soupapes de la douleur, formulée en 1965, était incomplète. Cela a conduit à la publication d'un chapitre d'ouvrage qui un jour allait définir, pour certains, la notion classique des mécanismes de la douleur. Or, ce chapitre a soulevé certains problèmes conceptuels pour la recherche sur les mécanismes de la douleur en utilisant le terme motivationnel/affectif pour définir un déterminant de la douleur. Pour faciliter la recherche et éventuellement améliorer les pratiques, les déterminants de la douleur doivent être clarifiés et quantifiés plus précisément. Dans le présent article, trois dimensions critiques de l'expérience sensorielle qui définissent la douleur et les expériences sensorielles associées sont identifiées : la prégnance sensorielle, l'affect et la dominance motivationnelle. Les auteurs montrent que chacune de ces dimensions peut être mesurée et qu'elles sont modulées par des mécanismes neurophysiologiques spécifiques. La douleur et autres sensations somatiques émergent des actions conjointes de ces systèmes neurophysiologiques et sont caractérisées par une définition précise des coordonnées définies de l'aire sensorielle tridimensionnelle qu'ils forment. Les mécanismes de la douleur seraient mieux compris si la recherche s'attardait à la physiologie et à la psychologie de ces dimensions sensorielles fondamentales et si elle incluait une plus vaste gamme de systèmes sensoriels.
$\mathrm{T}$ hirty two years ago, Melzack and Casey (1) wrote a paper that appeared as a chapter in The Skin Senses. The chapter, "Sensory, motivational, and central control determinants of pain" was an elaboration on the article, "Pain mecha- nisms: A new theory" (2), which presented the gate control theory of pain. The concept of gate control was preceded by Noordenbos' seminal book, simply titled Pain (3). This work, based largely on Noordenbos' clinical observations,

\footnotetext{
${ }^{1}$ Departments of Neurology and Physiology, University of Michigan, Neurology Research Laboratory, Veteran's Affairs Medical Center, Ann Arbor, Michigan, USA; ${ }^{2}$ Institute of Physiology, University of Hamburg, University Hospital Eppendorf, Hamburg, Germany

Correspondence and reprints: Dr Kenneth L Casey, VA Medical Center, 2215 Fuller Road, Ann Arbor, Michigan 48105, USA. Telephone 734-761-7562, fax 734-769-7035, e-mail kencasey@umich.edu
} 


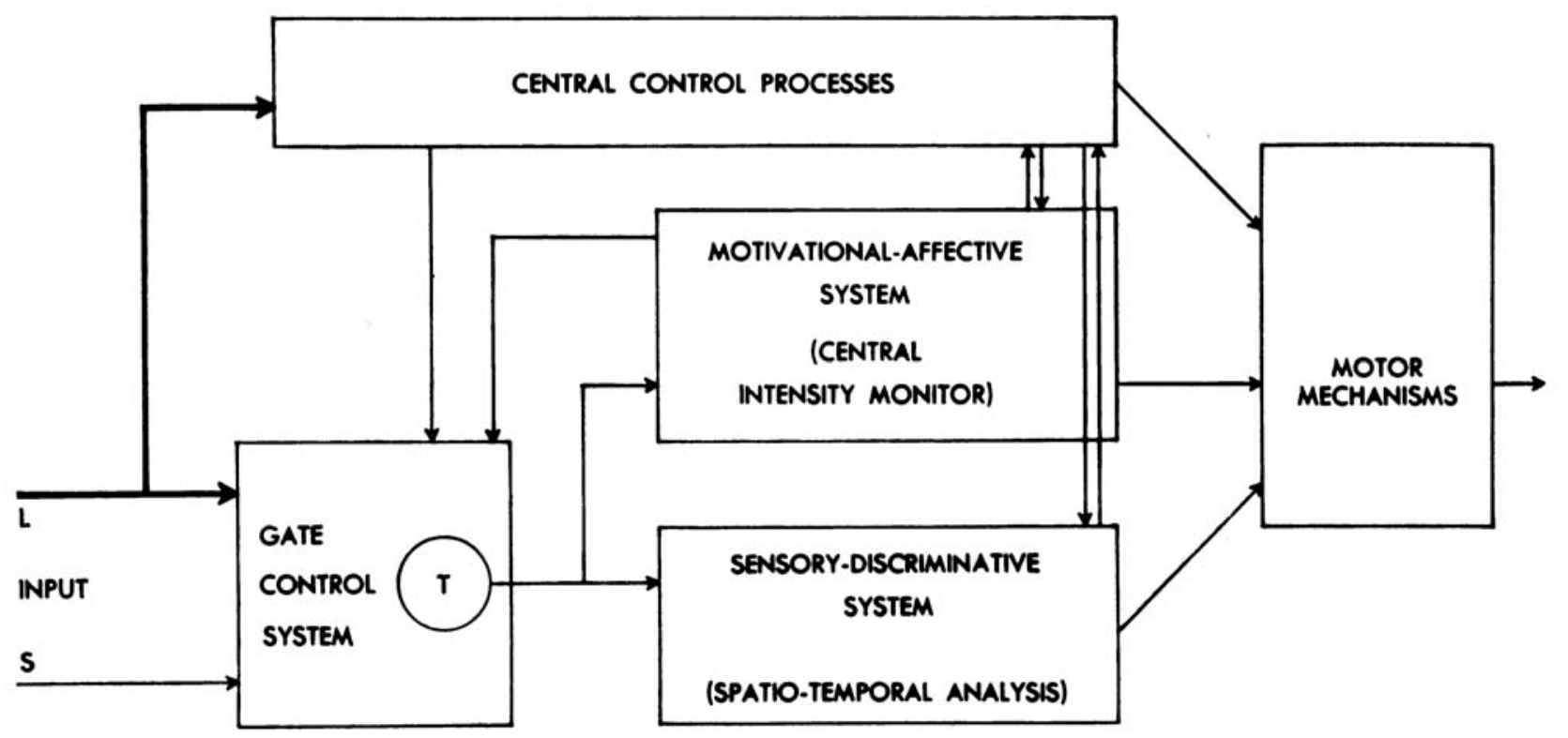

Figure 1) Conceptual diagram of the determinants of pain as presented by Melzack and Casey (1). The original legend reads as follows: “Conceptual model of the sensory, motivational, and central control determinants of pain. The output of the T cells of the gate control system project to the sensorydiscriminative system (via neospinothalamic fibers) and the motivational-affective system (via the paramedial ascending system). The central control trigger (comprising the dorsal column and dorsolateral projection systems) is represented by a line running from the large fiber system to central control processes. These, in turn, project back to the gate control system, and to the sensory - discriminative and motivational-affective systems. All three systems interact with one another, and project to the motor system." L Large diameter, myelinated afferent fibres; S Small diameter, finely mylinated or unmylenated afferent fibres

laid a foundation for the forthcoming gate hypothesis by presenting a challenge to prevailing concepts. The gate hypothesis was based on neurophysiological (4-6) and clinical (3) evidence available at the time, and rejected extreme 'peripheral' and 'pattern' concepts of pain mechanisms.

Ron Melzack recognized that the 1965 version of the hypothesis was incomplete. Gate control ended with the ' $T$ ' (transmission) cell in the spinal dorsal horn, which projected to a vaguely defined 'action system'. The 'action system' encompassed all supraspinal aspects of pain and was only briefly discussed in the gate hypothesis of 1965. Ron asked Ken Casey to join him in writing a chapter that would discuss in more detail what comprised the 'action system' of the gate hypothesis. Casey hesitated, thinking that the gate concept was quite enough for the time being and that pain could be left standing near the 'gate' - but Ron persisted. His exposure to the thinking of Donald Hebb (7) and William K Livingston (8-10) would not let him leave the complex physiology and experience of pain as a simple, sterile arrow at the end of a diagram. Many enjoyable and intellectually enriching discussions followed. Casey could not imagine then that this chapter would someday be referred to as 'the classical view' of pain mechanisms (11)!

Like most ideas that stick around, the basic concepts presented in "Sensory, motivational, and central control determinants of pain" (1) are easy to understand and were not very radical (Figure 1). Most scholars, investigators and clinicians have long considered that pain possesses the basic attributes of a sensation, such as the distinguishable characteristics of intensity, physical property (thermal, mechanical, chemical), and spatial and temporal location. It is perhaps only slightly more difficult to accept the idea that pain has a cognitive component, which affects the sensory aspects of pain and gives it contextual meaning based in large part on attention, past experience and expectation. At the time that "Sensory, motivational, and central control determinants of pain" was published, however, there was growing acceptance of the concept that brain mechanisms modulate sensory function. A neurophysiological basis for sensory modulation by supraspinal descending pathways had been presented by several investigators, including WK Livingston's son, Robert (12), among others (13-15).

\section{THE DETERMINANTS OF PAIN REVISITED}

The term 'motivational-affective' as a determinant of pain is ambiguous and presents significant conceptual problems. The term 'motivational' was originally used to indicate the engagement, by nociceptive pathways, of escape and avoidance behaviours. The term 'affective' represented the subjective, unpleasant aspect of pain (1). Over the ensuing years, these closely related terms have been subsumed under the designation 'unpleasantness'. However, as Fields (16) has pointed out, 'unpleasantness' has been used to refer to at least two aspects of pain - immediate ('primary unpleasantness') and delayed ('secondary unpleasantness'). The primary unpleasantness associated with the activation of nociceptive af- 
ferents is immediate and does not require cognitive evaluation. This is different from the secondary unpleasantness of pain, which follows a cognitive appraisal of the sensation and, through the recruitment of cortical forebrain mechanisms, may lead to delayed and long term emotional reactions and responses.

More needs to be learned about the neurobiology of primary unpleasantness by developing psychophysical methods to identify and quantify it more clearly. A major reason for making this psychophysical differentiation is that this dimension of pain is mediated by neural mechanisms that may be revealed in functional imaging studies and thus lead to a more detailed analysis of its neurophysiology. Fields (16) argued that a new term, 'algosity', is needed to differentiate primary unpleasantness from " that quality of an unpleasant somatic sensation that allows it to be identified as pain". We offer an alternative view that obviates the need for introducing yet another term into the pain literature. We suggest an approach that requires a different perspective. Our conceptual model is intended to provide a practical basis for analyzing the neural mechanisms of pain and related sensations; it is based on the following three propositions.

\section{Proposition 1: The term 'pain' (and its counterpart in other languages) is a universally recognized label for a unique somatic or visceral sensory experience}

This proposition requires little discussion. Were it not true, the International Association for the Study of Pain (IASP) would not exist and would certainly not have bothered to define pain. The IASP definition of pain is " an unpleasant sensory and emotional experience associated with tissue damage or described in terms of such damage" (17). We argue that, in common use, the label 'pain' serves the same purpose as Fields' proposed 'algosity'. It is highly unlikely that patients could be persuaded to use 'algosity' as a substitute for 'pain'. We do not address each of the elements in the IASP definition, in particular emotion, because an emotional experience requires neural processing at or near the level of complexity for cognition or 'secondary unpleasantness'. Our concern is with 'primary unpleasantness' in the sense used by Fields (16).

\section{Proposition 2: Pain is one of several unpleasant somatic or visceral sensations.}

This proposition is almost identical to Fields' statement (16). We only restate and emphasize the meaning of this statement for pain: (primary) unpleasantness at least partly determines pain but is not unique to pain. This seems obvious, but it is an important element in our proposal to clarify the relation between pain and primary unpleasantness.

\section{Proposition 3: Pain is determined by more than one measurable dimension of sensory experience, each of which is mediated by distinct neural mechanisms.}

This statement is the heart of our proposal. The proposition emphasizes an underlying concept of the 1968 model - that pain is determined by the dimensions of sensory experience.
In acknowledging that pain has multidimensional determinants, this proposition is in accord with the IASP definition and with the 'classical' conceptual model of pain (1). The key concept is that pain arises (is determined) as a consequence of the conjoint activity of neuronal systems that mediate unique aspects of sensory experience.

In developing our proposal, we identify and define three critical dimensions of sensory experience that define pain and other sensory experiences. We show that each of these dimensions can, in fact or principle, be measured and that pain falls within unambiguously defined coordinates of the three-dimensional sensory surface that they form. We show also that conceiving pain this way facilitates pain research by obviating the need to separate pain (or 'algosity') from the dimensions of sensory experience. These dimensions are determinants of pain, not elements of it.

\section{SOME DIMENSIONS OF SENSORY EXPERIENCE}

The dimensions of sensory experience are mediated by identifiable neural mechanisms. The activity of each of these neural systems is alone insufficient to mediate a particular sensation because a sensory experience requires their conjoint participation. We do not identify all dimensions of sensory experience. We only define those aspects of sensation that are especially relevant for clarifying the relationship of pain to the experience of primary unpleasantness.

\section{Sensory salience}

Sensory salience is perhaps the most fundamental property of all sensory experiences because behavioural action is otherwise limited to subconscious reflexes. It is the degree to which a stimulus, or a specific stimulus feature, is distinguished from others. One obvious measurable and detectable feature of a stimulus is intensity. We include other aspects of a stimulus under this term, however, including location, duration, and spatial or temporal frequency, all of which are independent and measurable features of a stimulus (18-20). It is obvious that normal sensory salience requires a normally functioning peripheral nervous system, spinal sensory mechanism and ascending pathways (21-24). Although recent functional brain imaging studies have revealed that intensity encoding is distributed among several brain structures $(25,26)$, both clinical and neurophysiological evidence show that the sensory features of all aspects of somatosensory stimuli are mediated primarily through the ventral posterior lateral thalamus (27-32), the primary and secondary somatosensory cortex, the insular cortex, and the posterior association cortex in the superior and inferior parietal lobules (33-37).

\section{Affect}

'Affect' is the spectrum of sensory experiences ranging from highly pleasant, through hedonically neutral, to highly unpleasant. We are concerned here only with the negative end of this spectrum. Like other dimensions of sensory experience, this can be scaled numerically and independently (38- 

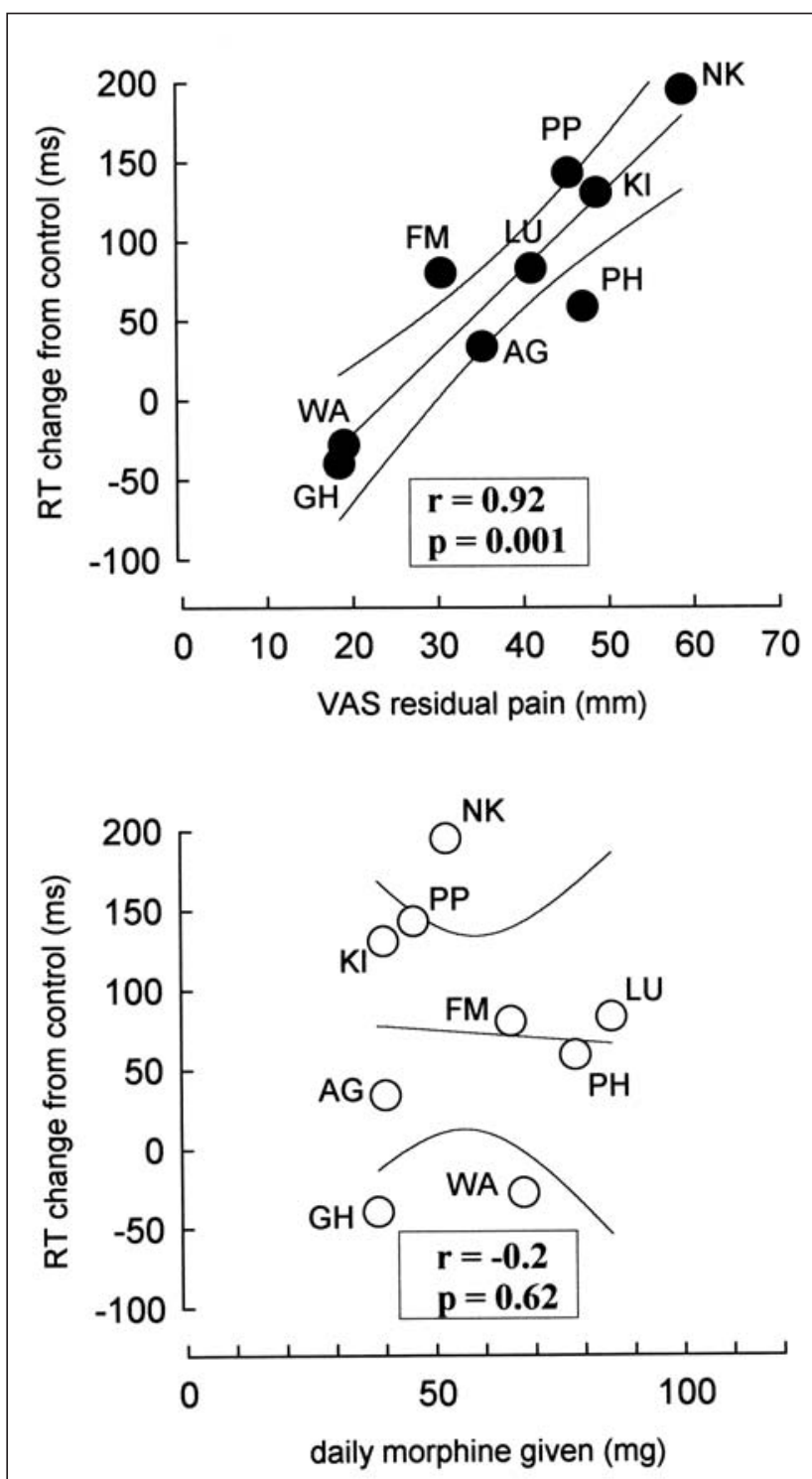

Figure 2) Effect of pain and morphine on reaction time in nine patients with pain from mucositis following bone marrow transplantation and immunosuppressive therapy. Reaction time (RT) in a forced-choice task was averaged over the period of pain. Change in RT was computed from the pain-free preoperative period and correlated significantly with residual pain (top) rated on a $100 \mathrm{~mm}$ visual analogue scale (VAS) $(0=$ no pain; $100=$ maximum pain). There was no significant correlation of change in RT with mean daily morphine infusion dose (bottom). The presented $r$ values are partial correlation coefficients that controlled for the correlation between residual pain and morphine dose. Note, for example, that patient WA received more daily morphine $(68 \mathrm{mg})$ than patients KI (40 mg) or NK (52 mg), had significantly lower residual pain (WA $19 \mathrm{~mm}$, $\mathrm{KI} 49 \mathrm{~mm}$, NK $59 \mathrm{~mm}$ ) and no deterioration in RT. Data from reference 72

40). There is substantial evidence that affect is mediated by neural mechanisms that are distinct from neural mechanisms mediating sensory salience. LeDoux (41) showed that, in experimental animals and humans, conditioning by aversive somatic stimulation occurs by amygdala-mediated subcortical mechanisms and does not require mediation or analysis through cortical systems $(42,43)$. Bernard and colleagues (44-46) elucidated the neurophysiological and anatomical characteristics of a nociceptive pathway linking the rodent spinal dorsal horn with the amygdala through the reticular formation, parabrachial nucleus, hypothalamus and thalamus. It is likely that these subcortical nociceptive systems with limbic system connections impart an intrinsic, possibly preconscious, aversiveness to the unconditioned stimuli used in behavioural studies. However, affect requires some level of conscious awareness and, at least in higher mammals, the participation of cortical components of the limbic system (47-55). Finally, it should be emphasized that affect and sensory salience interact strongly. For example, stimulus features near the lower limits of detectability are less likely to have strong affective weight than highly salient stimuli.

\section{Motivational dominance}

'Motivational dominance' is the degree to which a sensation determines behaviour, and is a sensory dimension because organisms that feel pain are consciously aware of the urgency associated with sensory events that are driving behaviour. Motivationally dominant stimuli are intrinsically difficult to ignore, cause repetitive interruption of ongoing behaviour, and usually result in annoyance and frustration. Motivational dominance interacts strongly with the other sensory dimensions but is especially modulated by cognitive processes that allocate attentional resources and govern executive choice functions. We are concerned here with the aspect of attention that is stimulus-driven and involves immediately orienting to certain salient and intrinsic features of a stimulus. This dimension of sensory experience is mediated through the activity of the midbrain $(56,57)$ and prefrontal cortex $(58-65)$, each of which interacts strongly with sensory and affective neural mechanisms. Like the other dimensions of sensory experience, motivational dominance can be separately identified and measured. Consequently, this dimension can be considered separately from the affective dimension, thus avoiding the ambiguity inherent in the term 'motivationalaffective' in the earlier formulation (1).

The motivational dominance of pain can be measured with interference paradigms, which are based on the observation that pain and mental tasks compete for attention. The measurements are reaction time and performance errors. The limited capacity of attention causes performance to drop when pain is present. There is strong evidence (cited below) that the motivational dominance of pain can be measured with both behavioural and physiological indicators.

Given a sufficiently demanding task, such as a complex version of the original Stroop test (66) or the Sternberg memory scanning test (67), clinical or experimental pain disrupts speed and accuracy $(66,67)$. Interference becomes more apparent when task demands are high and/or pain is intense and threatening (68). Catastrophic thinking styles and heightened somatic awareness also contribute to pain-induced performance deterioration (69).

These behavioural measures have neurophysiological correlates in humans. Lorenz and Bromm (70) recorded eventrelated cerebral potentials ( $\mathrm{P} 300)$ that respond to task-related stimuli during a visual Sternberg task or an auditory oddball 
task. Task performance and P300 amplitude both declined significantly during pain. In contrast, there was enhancement of a frontal negative potential (N275) in subjects with stable performance, suggesting that frontal lobe processes are involved in the voluntary effort to maintain performance under adverse conditions.

Relief from clinical pain also produces measurable changes in motivational dominance. The amplitude of the P300 potential evoked during an auditory oddball task increased significantly when patients obtained pain relief from chronic pain following opioid medication (71). Lorenz and colleagues (72) demonstrated that the effects of pain relief on motivational dominance could be differentiated from other physiological effects of the analgesic medication. Patients with severely painful mucositis following bone marrow transplantation performed a forced choice reaction time task each day before the onset of mucositis and during the treatment of mucositis pain with continuous intravenous morphine. Compared with the preoperative control period, the change of reaction time during mucositis pain correlated significantly with residual pain intensity (Figure 2, top). Reaction time did not correlate with the quantity of morphine given during the same time period (Figure 2, bottom). The intrusive nature of pain causes an involuntary displacement of attention and a concomitant loss of behavioural control, which is a measure of the motivational dominance of pain in this particular example.

\section{PAIN IS A COORDINATE IN SENSORY SPACE}

We have defined three dimensions of sensory experience that we propose are the major determinants of pain. However, these dimensions are also determinants of other sensations and are not unique to pain. These sensations share the subjective characteristics imparted to them by the dimensions of experience that we have defined. Somatic and visceral sensations are similar or different depending on the degree to which they share coordinates in sensory space (Figure 3).

Figure 3 shows the three axes that determine somatosensory experiences relevant to pain. Each unique sensation occupies a coordinate set on the 'stretched sheet' surface that describes the interaction among these determinants. Some of the sensations are labelled at various coordinates of the sensory surface (Figure 3). These labels (pain, allodynia, itch, dysesthesia) are used commonly to describe the sensations that occupy these coordinates. The labels are qualitative descriptors that, as far as we know, cannot be measured. Moreover, we know nothing of the neurophysiology mediating the application of these labels. We assume the coordinate position of these labelled sensations based only on our estimate of the relative neurophysiological contribution of each of the measurable dimensions.

We assume, based on the available evidence, that the psychophysical functions relating both sensory salience and affect to motivational dominance are positively accelerating $(73,74)$. Thus, for example, at any fixed level of perceived stimulus intensity (sensory salience), the motivational dominance of the sensation would increase rapidly as the input in-

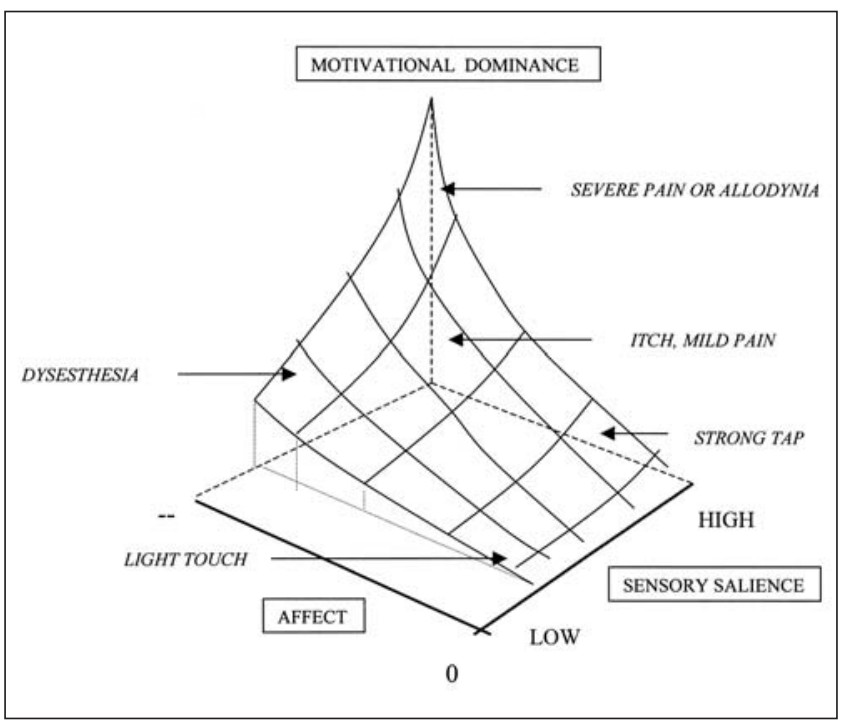

Figure 3) The sensory surface formed by the axes of the three dimensions of somatosensory experience (see text). Different somatosensory experiences (labelled arrows) occupy different regions of sensory space as determined by the influence of the neural mechanisms mediating each dimension. For example, at low levels of stimulus intensity (sensory salience), increasing the number of active nociceptive afferents (increasing negative affect) may have little effect on behaviour (motivational dominance), whereas behaviour is markedly affected by the addition of nociceptive activity at higher stimulus intensities. In pathological conditions, low intensities of afferent activity can have a strong negative affect; this may be experienced as dysesthesia (unpleasant touch) rather than pain. Slightly higher intensities produce allodynia. Without negative affect, however, as when no nociceptive afferents are active, even high intensities of stimulation have little effect on ongoing behaviour. For example, a strong tap, given as a friendly salutation, has high sensory salience but does not activate nociceptors and has little motivational dominance. The neural mechanisms mediating cognition, attention and emotion can modulate motivational dominance up or down along the sensory surface at any level of affect or salience; in addition, it may modulate the perceived level of these sensory dimensions. Note that sensations with different labels may occupy similar coordinates on the sensory surface despite different qualities (itch and mild pain, for example). The processes underlying the labelling of different sensations are not included as measurable sensory dimensions

cluded a larger proportion of $\mathrm{C}$ fibres, activated limbic forebrain structures and produced an increase in negative affect. The motivational influence of affect would be less with weak stimuli and much greater as perceived stimulus intensity increased (Figure 3). However, some highly salient stimuli, such as a congratulatory slap on the back ('strong tap' in Figure 3), have no negative affect and hence minimal motivational dominance. Similarly, at a fixed affective level, the motivational dominance of a sensation increases as perceived intensity increases, but the effect is much greater when nociceptive afferents are included in the input, increasing the negative affect. Severe pain and allodynia would occupy the coordinates at the highest levels of sensory salience and affective weight. At low levels of perceived intensity, only the most unpleasant, heavily affective sensations have motivational effects; we propose that pathological dysesthetic (unpleasant touch) sensations would occupy these coordinates. Below threshold levels of sensory salience, of course, affective weighting has no effect. 
Motivational dominance can modulate sensory salience and affect through subcortical mechanisms and cortically mediated cognitive processes that include attention (75), learning (65) and emotion (76-78). Given the lack of specific experimental data, we assumed that the sensory surface shown (Figure 3) describes the function mediating the bidirectional effect of cognitive and emotional mechanisms on motivational dominance, presumably acting jointly on both the sensory and affective determinants of sensation. For example, the learned fear of a stimulus could amplify its perceived intensity and affective weight (unpleasantness) (79), thus moving the coordinates of the sensation diagonally upward along the sensory surface. The opposite effect would occur when an ongoing behaviour, such as escaping a predator or playing an engaging game, enhances endogenous antinociception, captures attentional resources, and profoundly attenuates sensory salience and affect (80). These modulations of sensory and affective determinants would occur without changes in the physical characteristics of the stimulus or the neurophysiological properties of the afferent input signal.

\section{TESTING THE HYPOTHESIS OF SENSORY SPACE}

Because the dimensions defined here are each numerically and independently measurable, our hypothesis is testable in principle and practice. Our hypothesis is that the descriptive labels applied to somatic and visceral sensations occupy coordinates in the sensory space defined. If this is correct, then the effect of changing one variable while holding the others constant could be predicted. This would require experiments to determine the functions relating affective weighting, sensory salience and motivational dominance to one another. For example, an interference paradigm can measure motivational dominance as a dependent variable of interest in the present argument. Perceived stimulus intensity, which can be changed predictably and measured psychophysically, may be an independent variable. It is often not possible to vary stimulus intensity without changing affect, but it is possible for subjects to report conjoint changes in both of these experiences. These data could be obtained in a separate session before measuring the degree of stimulus interference with ongoing behaviour (motivational dominance). We predict that, as stimulus intensity increases, the degree of interference would increase along coordinates defined by a positively accelerating conjoint function of perceived intensity and weighted affect as suggested in Figure 3. We predict further that the descriptive labels applied to the stimulus would change as suggested in Figure 3. The affective weighting of the stimulus could be varied, perhaps by the application of various concentrations of capsaicin or mustard oil, which sensitize $\mathrm{C}$ fibres. By altering the physical nature of the stimulus, the site of application and the biochemical state of the tissue, it should be possible to change affective weighting and evoke a wide variety of somatic and visceral sensations. We predict that the positive exponent describing the effect of increasing perceived intensity on motivational dominance increases as a function of affect. This increase should have the form of the function relating affect to motivational dominance at a fixed intensity.

\section{THE SIGNIFICANCE OF THE SENSORY SPACE HYPOTHESIS FOR RESEARCH}

If the various somatic sensations are considered to emerge from the conjoint actions of separate but interacting neurophysiological systems, then researchers are not limited to formulating research questions around the labels that are commonly applied to these sensations. In this alternative view, there is no 'pain research', 'itch research' or 'dysesthesia research'. Rather, there is research on the determining dimensions from which each of these labelled sensations arise. Better progress may be made by investigating the physiological and psychological mechanisms underlying each of the dimensions of sensory space in other sensory systems. We could subsequently determine whether this information elucidates the mechanisms mediating somatosensory experiences. Affect, sensory salience and motivational dominance certainly share mechanistic features with other sensory systems, such as the chemical senses. Pain mechanisms would be better understood if research focused on the physiology and psychology of these fundamental sensory dimensions and included a wider range of sensory systems.

ACKNOWLEDGEMENTS: Supported by the National Institutes of Health/National Institute of Child Health and Human Development grant P01 HD33986, the Department of Veteran's Affairs (Merit Review grant) and the Max Kade Foundation. The authors thank Daniel Cutler for assistance with the illustration of Figure 3.

\section{REFERENCES}

1. Melzack R, Casey KL. Sensory, motivational, and central control determinants of pain. In: Kenshalo DR, ed. The Skin Senses. Springfield: CC Thomas, 1968:423-39.

2. Melzack R, Wall PD. Pain mechanisms: a new theory. Science 1965;150:971-9.

3. Noordenbos W. Pain. Amsterdam: Elsevier, 1959.

4. Wall PD. Excitability changes in afferent fibre terminations and their relation to slow potentials. J Physiol 1958;142:1-21.

5. Wall PD. The origin of a spinal cord slow potential. J Physiol 1962;164:508-26.

6. Mendell LM, Wall PD. Responses of single dorsal cord cells to peripheral cutaneous unmyelinated fibres, Nature 1965;206:97-9.

7. Hebb DO. The Organization of Behavior. New York: Wiley, 1949.

8. Livingston WK. Pain and Suffering. Seattle: IASP Press, 1998:1-250.

9. Livingston WK. Pain Mechanisms. New York: Macmillan, 1943.

10. Melzack R, Stotler WA, Livingston WK. Effects of discrete brain stem lesions in cats on perception of noxious stimulation. J Neurophysiol 1958;21:353-67.

11. Talbot JD, Marrett S, Evans AC, Meyer E, Bushnell MC, Duncan GH. Multiple representations of pain in human cerebral cortex. Science 1991;251:1355-8.

12. Adey WR, Segundo JP, Livingston RB. Corticofugal influences on intrinsic brainstem conduction in cat and monkey. J Neurophysiol 1957;20:1-16.

13. Hagbarth KE, Fex J. Centrifugal influences on single unit activity in spinal sensory paths. J Neurophysiol 1959;22:321-38. 
14. Lindsley DF, Adey WR. Availability of peripheral input to the midbrain reticular formation. Exp Neurol 1961;4:358-76.

15. Hernandez-Peon R. Modifications of tactile evoked potentials at the spinal trigeminal sensory nucleus during wakefulness and sleep. Exp Neurol 1965;13:40-57.

16. Fields HL. Pain: an unpleasant topic. Pain 1999;83(Suppl 6):S61-9.

17. Merskey H, Bogduk N. Classification of Chronic Pain: Descriptions of Chronic Pain Syndromes and Definitions of Pain Terms. Seattle: IASP Press, 1994:222.

18. Handwerker HO, Kobal G. Psychophysiology of experimentally induced pain. Physiol Rev 1993;73:639-71.

19. Craig JC. Somesthesis. Ann Rev Psychol 1999;50:305-31.

20. Gracely RH. Pain measurement. Acta Anaesthesiol Scand 1999;43:897-908.

21. Willis WD, Coggeshall RE. Sensory Mechanisms of the Spinal Cord. New York: Plenum, 1978:485.

22. Ruda MA, Bennett GJ, Dubner R. Neurochemistry and neural circuitry in the dorsal horn. Prog Brain Res 1986;66:219-68.

23. Light AR. Normal anatomy and physiology of the spinal cord dorsal horn. Appl Neurophysiol 1988;51:78-88.

24. Treede RD. Peripheral acute pain mechanisms. Ann Med 1995;27:213-6.

25. Derbyshire SW, Jones AK, Gyulai F, Clark S, Townsend D, Firestone LL. Pain processing during three levels of noxious stimulation produces differential patterns of central activity. Pain 1997;73:431-45.

26. Coghill RC, Sang CN, Maisog JH, Iadarola MJ. Pain intensity processing within the human brain: A bilateral, distributed mechanism. J Neurophysiol 1999;82:1934-43.

27. Mountcastle VB, Henneman E. The representation of tactile sensibility in the thalamus of the monkey. J Comp Neurol 1952;97:409-40.

28. Poggio GF, Mountcastle VB. The functional properties of ventrobasal thalamic neurons studied by unanesthetized monkeys. J Neurophysiol 1963;26:775-806.

29. Fisher CM. Lacunar strokes and infarcts: A review. Neurology 1982;32:871-6.

30. Adams RW, Burke D. Deficits of thermal sensation in patients with unilateral cerebral lesions. Electroencephalogr Clin Neurophysiol 1989;73:443-52.

31. Combarros O, Polo JM, Pascual J, Berciano J. Evidence of somatotopic organization of the sensory thalamus based on infarction in the nucleus ventralis posterior. Stroke 1991;22:1445-7.

32. Lenz FA, Kwan HC, Martin R, Tasker R, Richardson RT, Dostrovsky JO. Characteristics of somatotopic organization and spontaneous neuronal activity in the region of the thalamic principal sensory nucleus in patients with spinal cord transection. J Neurophysiol 1994;72:1570-87.

33. Head H, Holmes G. Sensory disturbances from cerebral lesions. Brain 1911;34:102-254.

34. Biemond A. The conduction of pain above the level of thalamus opticus. AMA Arch Neurol Psychiatry 1956;75:231-44.

35. Greenspan JD, Winfield JA. Reversible pain and tactile deficits associated with a cerebral tumor compressing the posterior insula and parietal operculum. Pain 1992;50:29-39.

36. Bushnell MC, Duncan GH, Hofbauer RK, Ha B, Chen JI, Carrier B. Pain perception: Is there a role for primary somatosensory cortex? Proc Natl Acad Sci USA 1999;96:7705-9.

37. Treede R-D, Kenshalo DR, Gracely RH, Jones AKP. The cortical representation of pain. Pain 1999;79:105-11.

38. Gracely RH, McGrath P, Dubner R. Ratio scales of sensory and affective verbal pain descriptors. Pain 1978;5:5-18.

39. Price DD, Barrell JJ, Gracely RH. A psychophysical analysis of experiential factors that selectively influence the affective dimension of pain. Pain 1980;8:137-50.

40. Price DD. Psychological and Neural Mechanisms of Pain. New York: Raven Press, 1988:1-241.

41. LeDoux JE. Emotional memory systems in the brain. Behav Brain Res 1993;58:69-79.
42. Romanski LM, LeDoux JE. Equipotentiality of thalamo-amygdala and thalamo-cortico-amygdala circuits in auditory fear conditioning. J Neurosci 1992;12:4501-9.

43. LaBar KS, Gatenby JC, Gore JC, LeDoux JE, Phelps EA. Human amygdala activation during conditioned fear acquisition and extinction: A mixed-trial fMRI study. Neuron 1998;20:937-45.

44. Bernard JF, Besson JM. The spino(trigemino)pontoamygdaloid pathway: Electrophysiological evidence for an involvement in pain processes. J Neurophysiol 1990;63:473-90.

45. Bernard JF, Alden M, Besson JM. The organization of the efferent projections from the pontine parabrachial area to the amygdaloid complex: a Phaseolus vulgaris leucoagglutinin (PHA-L) study in the rat. J Comp Neurol 1993;329:201-29.

46. Bernard JF, Bester H, Besson JM. Involvement of the spinoparabrachio-amygdaloid and -hypothalamic pathways in the autonomic and affective emotional aspects of pain. Prog Brain Res 1996;107:243-55.

47. MacLean PD. Visceral functions of the nervous system. Ann Rev Physiol 1957;19:397-416.

48. Hurt RW, Ballantine HT. Stereotactic anterior cingulate lesions for persistent pain: A report on 68 cases. Clin Neurosurg 1973;21:334-51.

49. Berthier M, Starkstein S, Leiguarda R. Asymobolia for pain: A sensory-limbic disconnection syndrome. Ann Neurol 1988;24:41-9.

50. Devinsky O, Luciano D. The Contributions of Cingulate Cortex to Human Behavior. In: Vogt BA, Gabriel M, eds. Neurobiology of Cingulate Cortex and Limbic Thalamus: A Comprehensive Handbook. Boston: Birkhauser, 1993.

51. Lenz FA, Gracely RH, Romanoski AJ, Hope EJ, Rowland LH, Dougherty PM. Stimulation in the human somatosensory thalamus can reproduce both the affective and sensory dimensions of previously experienced pain. Nat Med 1995;1:910-3.

52. Hugdahl K, Berardi A, Thompson WL, et al. Brain mechanisms in human classical conditioning: A PET blood flow study. Neuroreport 1995;6:1723-8.

53. Lenz FA, Gracely RH, Dougherty PM. The sensory-limbic model of pain memory: Connections from thalamus to the limbic system mediate the learned component of the affective dimension of pain. Pain Forum 1997;6:22-43.

54. Blood AJ, Zatorre RJ, Bermudez P, Evans AC. Emotional responses to pleasant and unpleasant music correlate with activity in paralimbic brain regions. Nat Neurosci 1999;2:382-7.

55. Hutchison WD, Davis KD, Lozano AM, Tasker RR, Dostrovsky JO. Pain-related neurons in the human cingulate cortex. Nat Neurosci 1999;2:403-5.

56. Redgrave P, McHaffie JG, Stein BE. Nociceptive neurones in rat superior colliculus. 1. Antidromic activation from the contralateral predorsal bundle. Exp Brain Res 1996;109:185-96.

57. Redgrave P, Simkins M, McHaffie JG, Stein BE. Nociceptive neurones in rat superior colliculus. 2. Effects of lesions to the contralateral descending output pathway on nocifensive behaviours. Exp Brain Res 1996;109:197-208.

58. Hardy SG, Leichnetz GR. Cortical projections to the periaqueductal gray in the monkey: a retrograde and orthograde horseradish peroxidase study. Neurosci Lett 1981;22:97-101.

59. Mesulam M-M. Frontal cortex and behavior. Ann Neurol 1986;19:320-5.

60. Fuster JM. The Prefrontal Cortex. New York: Raven Press, 1989.

61. Preuss TM, Goldman-Rakic PS. Connections of the ventral granular frontal cortex of macaques with perisylvian premotor and somatosensory areas: Anatomical evidence for somatic representation in primate frontal association cortex. J Comp Neurol 1989;282:293-316.

62. Raichle ME. Studies of the prefrontal cortex of normal human subjects: Contributions from modern imaging techniques. In: Thierry A-M, Glowinski J, Goldman-Rakic PS, Christen Y, eds. Motor and Cognitive Functions of the Prefrontal Cortex. Berlin: Springer-Verlag, 1994. 
63. Knight RT, Grabowecky MF, Scabini D. Role of human prefrontal cortex in attention control. Adv Neurol 1995;66:21-36.

64. Devinsky O, Morrell MJ, Vogt BA. Contributions of anterior cingulate cortex to behaviour. Brain 1995;118:279-306.

65. Hsieh JC, Stone-Elander S, Ingvar M. Anticipatory coping of pain expressed in the human anterior cingulate cortex: a positron emission tomography study. Neurosci Lett 1999;262:61-4.

66. Eccleston C, Crombez G, Aldrich S, Stannard C. Attention and somatic awareness in chronic pain. Pain 1997;72:209-15.

67. Lorenz J, Beck H, Bromm B. Cognitive performance, mood and experimental pain before and during morphine-induced analgesia in patients with chronic non-malignant pain. Pain 1997;73:369-75.

68. Crombez G, Eccleston C, Baeyens F, Eelen P. Attentional disruption is enhanced by the threat of pain. Behav Res Ther 1998;36:195-204.

69. Eccleston C, Crombez G. Pain demands attention: a cognitiveaffective model of the interruptive function of pain. Psychol Bull 1999;125:356-66.

70. Lorenz J, Bromm B. Event-related potential correlates of interference between cognitive performance and tonic experimental pain. Psychophysiology 1997;34:436-45.

71. Lorenz J, Beck H, Bromm B. Differential changes of laser evoked potentials, late auditory evoked potentials and P300 under morphine in chronic pain patients. Electroencephalogr Clin Neurophysiol 1997; 104:514-21.

72. Lorenz J, Baumgartner U, Zander AR, Bromm B. [Differentiation of pain-related and morphine-related impairment of cognitive performance and mood in bone marrow transplantation patients]. Der Schmerz 1996;10:80-8.

73. Price DD, McHaffie JG, Stein BE. The psychophysical attributes of heat-induced pain and their relationships to neural mechanisms. J Cogn Neurosci 1992;4:1-14.

74. Casey KL, Zumberg M, Heslep H, Morrow TJ. Afferent modulation of warmth sensation and heat pain in the human hand. Somatosens Motor Res 1993;10:327-37.

75. Miron D, Duncan GH, Bushnell MC. Effects of attention on the intensity and unpleasantness of thermal pain. Pain 1989;39:345-52.

76. Willer JC. Stress-induced analgesia in humans: endogenous opioids and naloxone-reversible depression of pain reflexes. Science 1981;212:689-90.

77. Hayes RL, Katayama Y. Range of environmental stimuli producing nociceptive suppression: implications for neural mechanisms. Ann NY Acad Sci 1986;467:1-13.

78. Yamada K, Nabeshima T. Stress-induced behavioral responses and multiple opioid systems in the brain. Behav Brain Res 1995;67:133-45.

79. Fanselow MS. Conditioned fear-induced opiate analgesia: a competing motivational state theory of stress analgesia. Ann NY Acad Sci $1986 ; 467 ; 40-54$

80. Hoffman HG, Doctor JN, Patterson DR, Carrougher GJ, Furness TA III. Virtual reality as an adjunctive pain control during burn wound care in adolescent patients. Pain 2000;85:305-9. 


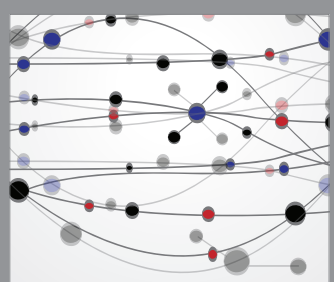

The Scientific World Journal
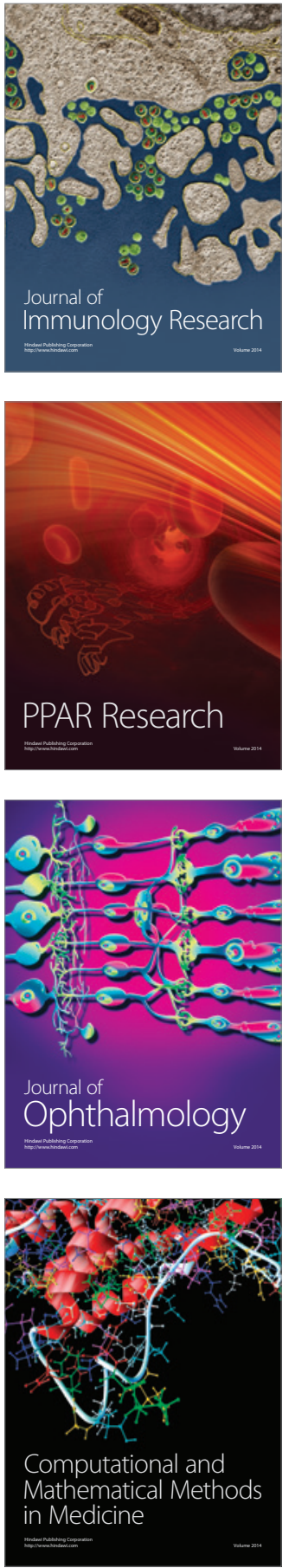

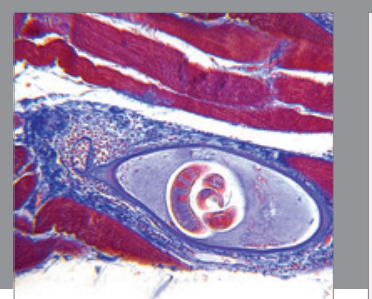

Gastroenterology Research and Practice

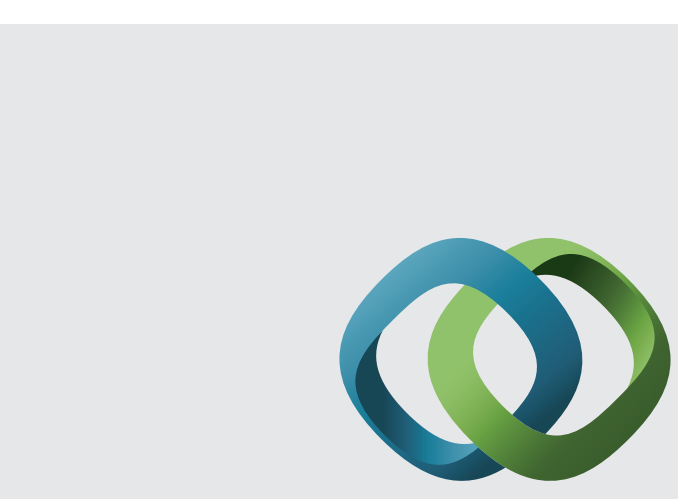

\section{Hindawi}

Submit your manuscripts at

http://www.hindawi.com
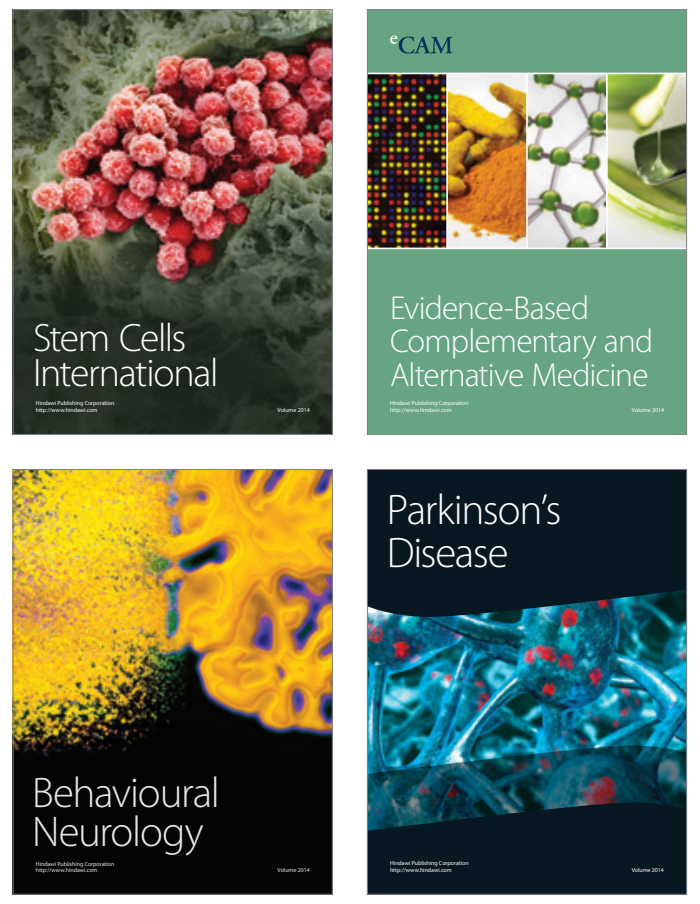
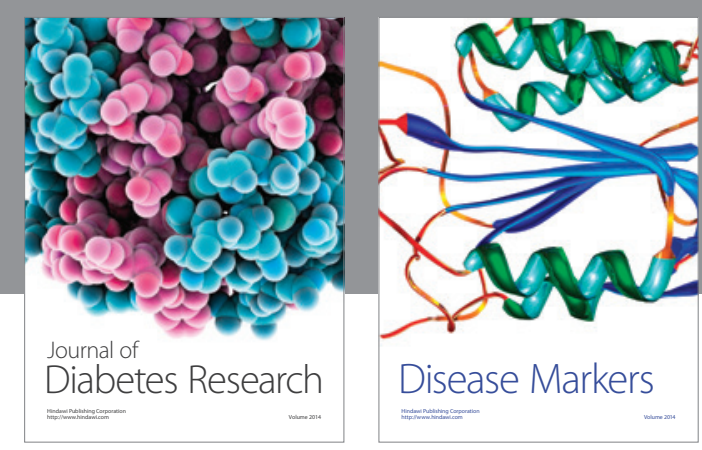

Disease Markers
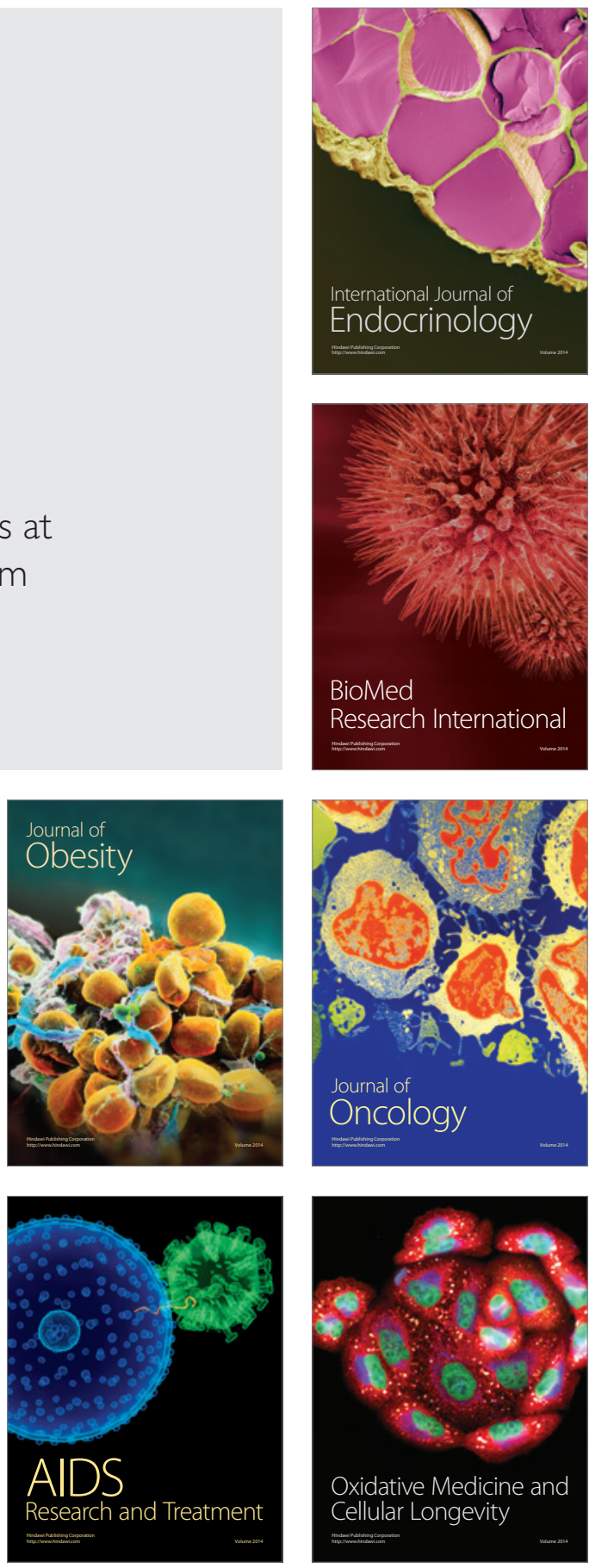